\title{
Implicit Dependency Regulation: Self-Esteem, Relationship Closeness, and Implicit Evaluations of Close Others
}

Tracy DeHart

Loyola University Chicago, tdehart@luc.edu

Brett Pelham

University at Buffalo

Sandra Murray

State University of New York

Follow this and additional works at: https://ecommons.luc.edu/psychology_facpubs

Part of the Psychology Commons

\section{Recommended Citation}

DeHart, T., Pelham, B., \& Murray, S. (2004). Implicit Dependency Regulation: Self-Esteem, Relationship Closeness, and Implicit Evaluations of Close Others. Social Cognition, 22(1), 126-146. doi:10.1521/ soco.22.1.126.30986

This Article is brought to you for free and open access by the Faculty Publications and Other Works by Department at Loyola eCommons. It has been accepted for inclusion in Psychology: Faculty Publications and Other Works by an authorized administrator of Loyola eCommons. For more information, please contact ecommons@luc.edu. (c) (i) $९$

This work is licensed under a Creative Commons Attribution-Noncommercial-No Derivative Works 3.0 License. (c) Guilford Press, 2004. 


\title{
IMPLICIT DEPENDENCY REGULATION: SELF-ESTEEM, RELATIONSHIP CLOSENESS, AND IMPLICIT EVALUATIONS OF CLOSE OTHERS
}

\author{
Tracy DeHart \\ University of Connecticut Health Center \\ Brett Pelham and Sandra Murray \\ University at Buffalo, State University of New York
}

\begin{abstract}
We argue that people possess implicit evaluations of close others and that dependency regulation processes moderate these implicit evaluations. Study 1 revealed that implicit evaluations of romantic partners for people with high explicit self-esteem were not contingent on how things were currently going in their relationships. In contrast, the implicit evaluations of romantic partners for people with low explicit self-esteem were contingent on how things were currently going in their relationships. That is, people with low self-esteem liked their partners' name letters only if the relationship was currently going well. Study 2 revealed a conceptually similar pattern of results for implicit evaluations of people's best friends. We suggest that these findings reflect an unconscious form of dependency regulation.
\end{abstract}

The quality of people's relationships tends to fluctuate over time. Unfortunately, disagreements and conflicts of interest are evident in even the closest of relationships. Almost universally, married couples promise to love one another "for better or worse." Friends promise to stick together "through thick and thin." Nonetheless, it is clear that many people find it easier to adore close others when things are going well in the relationship. Because rejection from close others can undermine self-esteem, people interpret events that occur in their relationships for evidence of whether a romantic partner loves them or whether a friend accepts them. However, people differ in how vigilant they are in reading signs of

Correspondence concerning this article should be addressed to Tracy DeHart, Department of Psychiatry, University of Connecticut Health Center, Farmington, CT, 06030. E-mail: dehart@psychiatry.uchc.edu. 
rejection into their significant other's behavior. The same remark that is interpreted as a well-intended joke by one person may be interpreted as evidence of rejection by another. What determines these differing perceptions?

Just as people differ in their chronic needs for interpersonal acceptance (Leary, Tambor, Terdal, \& Downs, 1995), they may also differ in their needs for acceptance in specific relationships. For example, many people with low self-esteem have a history of feeling rejected and are thus especially sensitive to cues of rejection. Conversely, most people with high self-esteem have a history of feeling accepted and are thus less sensitive to cues of rejection. In any specific relationship, then, people with low self-esteem may be less likely to find the sense of confidence in a partner's acceptance they need to risk feeling attached to that relationship (Murray, Holmes, Griffin, 2000).

\section{DEPENDENCY REGULATION}

According to the dependency regulation model, people regulate attachment to close others in a self-protective way, only allowing themselves to become dependent upon partners when the risk of rejection is perceived to be minimal (e.g., Berscheid \& Fei, 1977; Bowlby, 1982; Holmes \& Rempel, 1989; Murray et al., 2000). That is, people only allow themselves to become attached to a significant other when they can find a sense of felt security in that specific person's love and acceptance (DeHart, Murray, Pelham, \& Rose, 2003; Murray et al., 2000; Murray, Holmes, Griffin, Bellavia, \& Rose, 2001). For example, people view their romantic partners more positively the more positively they believe their partners views them (Murray et al., 2000) and the more they feel loved (Murray et al., 2001). Conversely, people may distance themselves from their relationships and devalue significant others if they do not feel certain of their partners' love and acceptance.

Unfortunately, people who are chronically low in self-esteem typically doubt even their closest relationship partners' true affections for them. For instance, people with low self-esteem underestimate how positively their dating and marital partner views them on specific traits (Murray et al., 2000) and even underestimate how much their romantic partner and family members love them (DeHart et al., 2003; Murray et al., 2001). In contrast, people with high self-esteem more accurately perceive how positively they are viewed (and how much they are loved) by close others.

Given chronically activated concerns about the partner's acceptance, people with low self-esteem then approach their relationships in a hypothesis-testing fashion, scrutinizing their partners' behavior for information about caring. As a consequence, even potentially benign events, 
such as a partner simply being in a bad mood, are imbued with pessimistic inferences about caring (Bellavia \& Murray, 2003). To add insult to injury, detecting such signs of rejection is most personally hurtful for people who lack a protective sense of felt security in the partner's acceptance. That is, people who feel less positively regarded by their spouse internalize felt rejections, reporting lower self-esteem on days after they felt more rejected by their spouse than usual (Murray, Griffin, Rose \& Bellavia, 2003a).

In situations where they feel acutely rejected, people who feel less accepted and valued, such as people low in self-esteem, then protect themselves against this hurt by self-protectively reducing their dependence on the partner. For example, people with low self-esteem react to mundane signs of relationship difficulty, such as a partner's annoyance, by defensively devaluing their partner's traits, and by reducing their own feelings of closeness (Murray, Holmes, MacDonald, \& Ellsworth, 1998; Murray, Rose, Bellavia, Holmes \& Kusche, 2002). In contrast, people with high self-esteem react to signs of potential rejection by maintaining, and sometimes embellishing their positive regard for their partners.

\section{DO DEPENDENCY REGULATION PROCESSES OCCUR AUTOMATICALLY?}

To the extent that people with low self-esteem repeatedly read potential rejection into ambiguous situations, and repeatedly respond to rejection by devaluing their relationship partners, these self-protective dynamics should eventually become over-learned, and thus, relatively automatic. That is, after years of responding to interpersonal threats and stressors in the same basic fashion, people's responses (whether favorable or unfavorable) may become routinized. Previous research on dependency regulation has assumed that these defensive processes are to a great degree unconscious (Murray et al., 2003a). Presumably, people with low self-esteem are not consciously aware that they are derogating their partners to protect themselves against potential rejection. However, previous research has not examined whether the outcomes of such dependency regulation processes are also evident on an implicit level. That is, past research on the dependency regulation model has focused only on people's explicit or consciously considered beliefs about their relationship partners. Previous research has not assessed whether people's implicit associations about their close relationship partners change in ways that are consistent with the predictions of the dependency regulation model.

Nonetheless, there is some evidence in the close relationships literature that people's beliefs about and responses to their relationship part- 
ners may become automatized (e.g., Andersen \& Chen, 2002; Bowlby, 1982; Mikulincer, Gillath, \& Shaver, 2002). According to attachment theorists, caretakers' habitual responses to infants become internalized into infants' working mental models. Importantly, attachment theorists describe people's mental models as a set of both conscious and unconscious beliefs about the self in relation to other people (Bowlby, 1982). Attachment theorists have also argued that attachment beliefs become activated during times of interpersonal threat. For instance, recent research has demonstrated that threatening situations automatically activate people's beliefs and associations about important attachment figures (Mikulincer et al., 2002).

An additional reason to believe that people may automatically regulate their beliefs about close others comes from research suggesting that people automatically regulate their beliefs about themselves (Dodgson \& Wood, 1998; Jones, Pelham, Mirenberg, \& Hetts, 2002; Koole, current issue). For example, Koole (current issue) found that in response to self-threat people who are action-oriented versus state-oriented differed in their implicit autonomy related evaluations assessed using an evaluative priming task. Whereas action-oriented participants maintained or enhanced their implicit autonomy related evaluations, state-oriented participants showed a decrease in implicit autonomy evaluations. In addition, Dodgson and Wood (1998) found that after a failure manipulation, people with high versus low explicit self-esteem exhibited differences on a response latency measure of implicit self-evaluation. More specifically, after a failure manipulation, participants high in explicit self-esteem recruited thoughts about their personal strengths and suppressed thoughts about their weaknesses (compared with participants low in explicit self-esteem).

Consistent with these findings, Jones et al. (2002) asked participants high versus low in explicit self-esteem to write about (1) an aspect of themselves that they did not like and could not change, (2) a positive aspect of themselves, or (3) the last movie they had seen (a control condition). After the experimental manipulation participants were asked to fill out a name-letter measure of implicit self-esteem. The only difference between participants high versus low in explicit self-esteem occurred in the self-threat condition. Whereas participants high in explicit self-esteem in the self-threat condition reported elevated liking for their name letters, participants low in explicit self-esteem showed the reverse effect. Thus, Jones et al. (2002) showed that people's level of explicit self-esteem moderates their implicit responses to negative events. More specifically, people high in explicit self-esteem appear to be more adept at defending the self in the face of threat. Importantly, Jones et al. suggested that this form of psychological self-defense often occurs unconsciously. 
The idea that a great deal of self-defense occurs unconsciously is consistent with several self-protective strategies (Sedikides \& Green, current issue; Stapel \& Schwinghammer, current issue; Wentura \& Greve, current issue). For example, Sedikides and Green's model of mnemic neglect suggests that people are less likely to recall self-threatening information, especially if the information threatens their core self-concept. In addition, Wentura and Greve's research on self-immunization showed that people changed the criteria they used to evaluate their knowledge to correspond to the information they knew. Presumably, these self-protective strategies are successful because people are unaware that they are using them. Consistent with this idea, Stapel and Schwinghammer's research showed that people are not at liberty to use self-protective strategies to defend the self against unambiguous upward social comparisons. That is, the use of defensive social comparisons may be constrained to situations where the comparisons are believable, and perhaps unconscious.

Just as people defend their beliefs about themselves, they also appear to defend their beliefs about significant others. More specifically, people in satisfying relationships typically engage in relationship-enhancing attributions for their partners' negative behaviors (Bradbury \& Fincham, 1990), and may misunderstand their partners' thoughts in situations where insight would prove threatening (Simpson, Ickes, \& Blackstone, 1995). However, the dependency regulation model suggests that people's ability to defend their relationship from threats is constrained by their confidence that their partners truly accept them. As noted previously, people high versus low in self-esteem differ in their felt security in close relationships. Accordingly, the beliefs about close others that are automatically activated in relationship threatening situations may differ for people with low versus high self-esteem.

Although past research suggests that implicit beliefs are fairly stable and resistant to change compared with explicit beliefs (Hetts, Sakuma, \& Pelham, 1999), recent research has documented that people's implicit beliefs can be dynamic and change in response to environmental influences (e.g., DeHart \& Pelham, 2003a; Dijksterhuis, in press; Jones et al., 2002; Koole, current issue). According to the dependency regulation model, relationship-specific expectancies of acceptance play a central role in regulating people's perceptions of their partners. Therefore, people with low self-esteem should value their partners if they believe their partners accept them, but they will devalue their partners if they believe their partners will reject them. We believe that it is precisely the contingency between perceived acceptance and people's regard for their relationship partners that becomes overlearned, not just a stable positive (or negative) association for attachment figures as attachment theory might suggest (e.g., Mikulincer et al., 2002). 
How might one assess people's automatic evaluations of close others? One simple way is based on research on the name-letter effect. This research shows that the automatic implicit associations people have about themselves are reflected in their liking for the letters that appear in their own names (Hoorens \& Nuttin, 1993; Jones et al., 2002; Kitayama \& Karasawa, 1997; Koole, Dijksterhuis, \& van Knippenberg, 2001; Nuttin, 1985; 1987). If people's liking for the letters in their own names reflects the favorability of their implicit associations to the self, it stands to reason that people's liking for the letters in the names of significant others may reflect the favorability of their implicit associations about these significant others.

\section{STUDY 1}

In Study 1 we hoped to extend work on dependency regulation by assessing whether people's implicit evaluations of their romantic partners would be a joint product of their own self-esteem levels and their current feelings about their partners. We used people's reports of how close they felt to their partners because we believe that reduced feelings of closeness are an indirect proxy for current anxieties about rejection. Specifically, we expected that people with low self-esteem would report favorable implicit evaluations of their romantic partner only when their relationship was going well. On the other hand, when the relationships of people with low self-esteem are not going well, they should feel less valued and read more potential rejection into their interactions with their partners (Murray, Bellavia, Rose, \& Griffin, 2003b). As a result, people with low self-esteem should report less favorable implicit evaluations of their romantic partners. In contrast, we expected that people with high self-esteem should report favorable implicit evaluations of their partners regardless of how their relationship was currently going.

\section{METHOD}

\section{PARTICIPANTS}

Health care workers enrolled in a continuing education workshop in Tallahassee or Panama City, FL (73 women and 26 men) participated in a study of social attitudes. Data from 15 participants who reported being single were excluded from our analyses, leaving 61 women and 23 men. The large majority of these participants $(88.1 \%)$ reported being married, and the remainder reported either that they were seriously $(9.5 \%)$ or casually $(2.4 \%)$ dating. Mean age was 46.4 years $(S D=11.3)$. 


\section{PROCEDURE}

At the beginning of a workshop, participants completed a 2-page survey that focused on their "social attitudes and perceptual judgments and preferences." Participation in the survey was voluntary, and all responses were anonymous. Participants answered background questions about their current romantic relationship status, and then completed a measure of global self-esteem, followed by a name-letter measure. Once all participants had completed the survey, they responded to a verbal request to enter both their partners and their own first and last initials at the end of the survey. It is thus extremely unlikely that participants could have anticipated our interest in their evaluations of their own or their partners' initials while completing the survey. Participants later learned how the measures in their survey could be used to assess people's implicit and explicit evaluations of self and close others.

\section{MEASURES}

Relationship Status. Participants reported their current romantic relationship status by circling one of several options (e.g., married, casually dating) in the first section of the survey.

Relationship Quality. Participants reported how well their romantic relationship was currently going by responding to two items ("If currently in a relationship, please report how your relationship has been going for the past week" and "If currently in a relationship, how close do you feel to your current romantic partner?"). Participants responded to these items on 7-point scales (respectively, $1=$ much worse than usual, $7=$ much better than usual; and $1=$ not at all close, $7=$ extremely close). The two items were averaged so that higher scores reflected higher current relationship quality $(\alpha=.64)$.

Explicit Self-Esteem. Participants reported their level of global self-esteem using Robins, Hendin, and Trzesniewski's (2001) single-item self-esteem scale ("On the whole, would you say that you have high self-esteem?"). Participants responded to this item using a 7-point scale ( $1=$ not at all, $7=$ very much so $)$.

Implicit Evaluation of Partner. Our measure of people's implicit evaluations of their romantic partners was based on research on the name-letter effect (Jones et al., 2002; Kitayama \& Karasawa, 1997; Koole et al., 2001; Nuttin, 1985; 1987). Specifically, we asked participants to report their preferences for each of the 26 letters of the alphabet. Presumably, these ratings were to be used to "develop stimuli for future studies of linguistic and pictorial preferences." Participants were asked to "trust your intuitions, work quickly, and report your gut impressions" (emphasis in original). Participants made their ratings using a 9-point scale ( $1=$ dis- 
like very much, $9=$ like very much). Name-letter preferences are documented to the degree that people whose names contain specific letters evaluate those letters more favorably than do people whose names do not contain the same letters. Because past research has shown that name letter preferences are most pronounced for people's initials, we assessed only people's partners' initials in this research. Consistent with past research on own name-letter preferences, our dependent measure was the degree to which participants rated their partners' initials more favorably than did people whose own initials (or whose partners initials) did not include a specific letter (for more details on scoring name-letter measures, see DeHart \& Pelham, 2003b; Jones et al., 2002; Koole et al., 2001).

\section{RESULTS}

Do people's implicit evaluations of their partners follow the pattern suggested by the dependency regulation model? ${ }^{1}$ To test this idea, we examined the joint effects of explicit self-esteem and current relationship quality (both continuous variables) on people's liking for their romantic partners' name-letters. To do so, we followed the procedures outlined by Aiken and West (1991) for testing interactions in multiple regression. Specifically, we centered our two predictors (by subtracting the appropriate sample means) and then used these centered predictors in our analyses. The predictors in this simultaneous regression equation were thus (a) explicit self-esteem, (b) current relationship quality, and (c) the interaction (cross-product) term for these two variables. Our criterion variable was the average of participant's liking scores for their romantic partners' first and last name initials $(\alpha=.48)$. We expected participants' preferences for their partner's initials to depend on both their own self-esteem levels and the current climate of their relationships. As summarized in Table 1, this was the case. Specifically, we observed a significant Explicit Self-esteem $\times$ Relationship Quality interaction, $B=-.26, \beta=$ $-.26, t(74)=-2.16, p=.03$. As suggested by the regression lines appearing in Figure 1, simple slopes tests revealed that the current quality of people's romantic relationships was only associated with partner name-letter liking for those with low self-esteem, $B=.63, \beta=.45, t(74)=2.65, p=$ .01. For those with high self-esteem, there was no relation at all between the current relationship quality and partner's name-letter liking, $B=$ $-.13, \beta(=-.09, t(74)=-.56, p=.58$. In short, whether the current quality of

\footnotetext{
1. One sample t-tests revealed that participants reported an overall positive bias for their partner's first $(M=.74, S D=2.07), t(79)=3.21, p<.01$, and last initials $(M=.92, S D=2.13), t$ $(77)=3.81, p<.001$.
} 
TABLE 1. Explicit Self-Esteem, Relationship Quality and Romantic Partner's Name-letter Preferences

\begin{tabular}{lrrrr}
\hline & $B$ & $\beta$ & $t$ & $p$ \\
\hline Self-Esteem & .05 & .04 & .37 & .71 \\
Relationship Quality & .25 & .18 & 1.62 & .11 \\
Self-Esteem $\times$ Relationship Quality & -.26 & -.26 & -2.16 & .03 \\
\hline
\end{tabular}

people's relationship was associated with people's preferences for their partner's initials depended heavily on people's level of self-esteem. People low in self-esteem only took a shining to their partners' initials when things had recently been looking particularly bright in their relationships.

\section{DISCUSSION}

Our results are consistent with previous research showing that people with low self-esteem distance themselves from their relationship partners during times of difficulty. That is, when things go wrong in the relationships of people with low self-esteem, they distance themselves from their partners, presumably as a way of protecting themselves from potential rejection. This form of relationship regulation apparently occurs at a level beyond people's conscious awareness. However, a potential problem with the current study is that it is difficult to disentangle self and partner evaluation. Because we averaged people's liking for their partner's first and last initials, and because most of our participants shared the same last initial as their partners, it is possible that our findings regarding implicit dependency regulation reflect only implicit self-regulation processes. We assume that, among married couples in which women have taken on their husbands' surnames, it is the initial that people share with their partners (the surname initial) that more strongly symbolizes their relationship with this partner. Thus, it would not be too surprising, or distressing, if our dependency regulation findings were stronger in the case of the last as opposed to first initials of people's romantic partners. To test this idea, we dummy coded whether participants shared their partners' surname initials, and tested for whether the 2-way Self-esteem $\times$ Relationship Quality interaction was moderated by a 3-way interaction involving surname sharing. It was not ( $p=.46$ for the 3 -way interaction).

To complicate matters slightly, however, our dependency regulation findings did appear somewhat stronger when we focused on the last as 


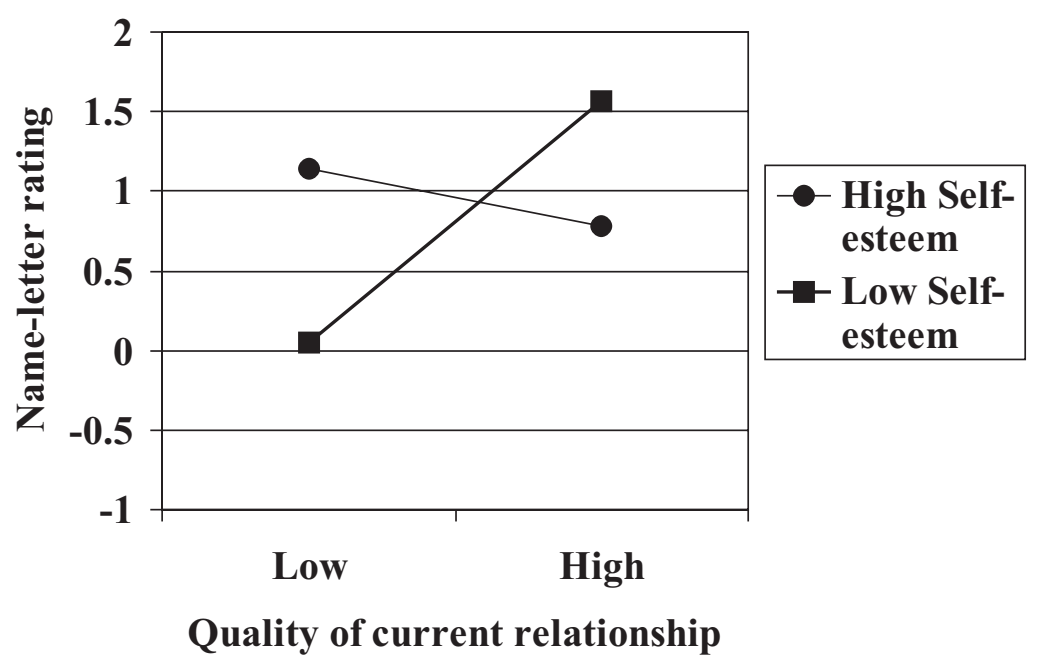

FIGURE 1. Predicting partner's name-letter rating from self-esteem and the current quality of the relationship.

opposed to first name initials of participants' romantic partners. When we repeated our primary analyses separately for people's liking of their partner's first and last name initials, the results for partners' last initials were significant $(p=.03)$. However, the results for partners' first initials reflected only a trend in the same direction $(p=.18)$. Finally, although only a small number of participants had a first or surname initials that differed from their partners' initials, a close look at their data suggested that, among these participants, the dependency regulation effects we observed tended to be strongest for their partners' first initials (an initial that clearly referred only to their partner), $B=-.82, \beta=-.84, t(13)=-2.01, p$ $=.07$. In addition, when we reran the Explicit Self-esteem $\times$ Relationship Quality interaction predicting how much people liked their partners first and last name initials, with their own first name initial liking as a covariate, the interaction was still marginally significant, $B=-.22, \beta=$ $-.22, t(74)=-1.92, p=.06$. In short, the available evidence suggests that our dependency regulation findings truly reflect people's evaluations of their partners rather than merely reflecting self-evaluation. Nonethe- 
less, the interpretation one prefers for the findings of Study 1 might depend on the degree to which one privileges the independent versus the collective or socially shared self.

In Study 2 we attempted to extend our findings by examining a close relationship in which people typically do not share the same surname initial—namely, friendship. Based on our previous work on the specificity of name-letter preferences (DeHart \& Pelham, 2003b; Hetts \& Pelham, 2003), we expected that people's implicit evaluations of their best friends might be best captured by their liking for their friends' first initials. After all, people typically refer to (and think about) close friends by using their friends' first names. In fact, one of the social markers of friendship is be able to refer to a person "on a first name basis." Nonetheless, for exploratory purposes, we assessed people's liking for their friends' last initials as well.

In Study 2, we also addressed the question of whether people's implicit evaluations of close others are independent of their explicit evaluations of the same people. There is a great deal of research suggesting that implicit and explicit belief systems operate independently of one another (e.g., Banaji \& Hardin, 1996; Greenwald, McGhee, \& Schwartz, 1998; Hetts et al., 1999; Koole \& Pelham, 2002). People's implicit evaluations of their relationship partners may thus be unique predictors of relationship vulnerabilities. Thus, unlike participants in Study 1, participants in Study 2 completed an explicit as well as an implicit measure of their evaluations of their relationship partners. Finally, due to time constraints in Study 1, we assessed explicit self-esteem using a single-item self-esteem scale. In Study 2, we made use of a multiple-item measure.

\section{STUDY 2}

In Study 2 we looked at people's implicit evaluations of their best same-sex friends. We expected that dependency regulation dynamics would play a role in these evaluations. Thus, we expected that people with low self-esteem would report positive implicit evaluations of their friends only when they also reported feeling close to these friends. In contrast, we did not expect the implicit evaluations of people with high self-esteem to depend on how close they reported feeling to their friends.

\section{METHOD}

\section{PARTICIPANTS}

Students (72 women and 36 men) in a research methods course at the State University of New York at Buffalo participated for course credit. 
Participation was voluntary and anonymous. Students received extra course credit for attending class the day the questionnaire was administered, even if they chose not to participate. Mean age was 21.5 years (SD =3.58). Data were lost from 19 participants because they failed to complete all of the primary measures.

\section{OVERVIEW OF PROCEDURE}

During a regular class session, students took part in a survey that focused on their "attitudes and close relationships." Participants completed an explicit measure of self-esteem, the name-letter measure, and an explicit measure of their esteem for their best friend. Finally, they completed a measure of relationship closeness and reported their own first and last initials. As explained below, it was unnecessary to ask participants for their friends' initials because they provided these initials when reporting their explicit feelings of esteem for their friend.

\section{MEASURES}

Explicit Self-Esteem. We used the Rosenberg (1965) self-esteem scale to measure explicit self-esteem. This 10-item measure taps people's explicit global self-evaluations (e.g., "I feel that I have a number of good qualities"). Participants responded using a 7-point scale $(1=$ completely true, $7=$ not at all true). Negative items were reverse-scored, such that higher scores indicated higher self-esteem $(\alpha=.90)$.

Implicit Evaluation of Friend. We used the same name-letter measure used in Study 1 (Jones et al., 2002; Kitayama \& Karasawa, 1997; Nuttin, $1985 ; 1987)$.

Explicit Evaluation of Friend. We adapted the Rosenberg (1965) self-esteem scale to measure people's global, explicit evaluations of their best same-sex friends. Participants were asked to write the first and last name initials of their best same-sex friend in each blank of the 10-item measure to show that they were answering each question about that particular person (e.g., "I feel that ___ has a number of good qualities"). Because this measure followed the name letter measure, it could not have sensitized participants to our interest in their friends' initials.

Closeness. One item assessed how close participants felt to their best friend (e.g., "How close are you to your best same-sex friend?"). Participants answered this question on a 7 -point scale $(1=$ not at all close, $7=$ extremely close). 


\section{RESULTS}

As shown in Table 2, Study 2 yielded a conceptual replication of Study $1 .^{2}$ More specifically, participants' preferences for their friends' first name initials differed depending on both participants' level of explicit self-esteem and their current feelings of closeness to their friends. ${ }^{3}$ The Self-esteem $\times$ Closeness interaction was significant, $B=-.65, \beta=-.28, t$ $(87)=-2.68, p<.01{ }^{4}$ The regression lines depicted in Figure 2 summarize our simple slopes tests. Among people with low self-esteem, how close they reported feeling to their best friends was positively associated with their preference for their friends' first initials, $B=1.24, \beta=.59, t(87)=$ $3.34, p=.001$. In contrast, for participants with high self-esteem, there was no relation at all between how close they reported feeling to their best friend and how much they liked their friends' first initials, $B=-.17, \beta$ $=-.08, t(87)=-.55, p=.58$. Whether people's current feelings of closeness to their friends was associated with people's preferences for their friend's initials depended heavily on people's level of self-esteem.

Were people's implicit evaluations of their best friends independent of their explicit evaluations? When we repeated our original analysis but controlled for people's explicit evaluations of their friends we observed the same significant Self-esteem $\times$ Closeness interaction. In addition, we repeated the above Self-esteem $\times$ Closeness interaction substituting people's explicit evaluation of their best friends for their implicit evaluations. This analysis revealed that self-esteem did not moderate the association between closeness and people's explicit evaluations of their best friends, $B=-.04, \beta=-.05, t(95)=-.59, p=.56$. Therefore, these results suggest that people's implicit evaluations of their friends appear to be independent of their explicit evaluations of them. We might have failed to observe any systematic variation in people's explicit appraisals of their best friends because the measure of explicit appraisals focused on global evaluations of the partner rather than judgments about specific traits (as was typical in prior research). It is also possible that the level of threat that people were currently experiencing in their friendships was

2. A similar Self-esteem $X$ Closeness interaction was not evident when predicting people's preference for their best friend's last name initial, $B=.03, \beta=.01, t(87)=.10, p=.91$.

3. One sample t-tests revealed a non-significant tendency for participants to report an overall positive bias for their friend's first $(M=.27, S D=1.98), t(92)=1.34, p=.18$, and last initials $(M=.28, S D=2.07), t(92)=1.29, p=.20$.

4. Before the name-letter measure participants completed either a friend prime (answered five questions about their best friend) or a control manipulation (answered five questions about their favorite state). There was no significant Prime Condition $\times$ Self-esteem $\times$ Closeness interaction, $B=-.21, \beta=-.15, t(83)=-.39, p=.70$. This null effect suggests that people's implicit associations about their friends are chronically accessible (i.e., they are not contingent on whether people have been recently primed to think about a friend). 
TABLE 2. Explicit Self-Esteem, Closeness and Friend's First Name-letter Preferences

\begin{tabular}{lrrrr}
\hline & $\boldsymbol{B}$ & $\boldsymbol{\beta}$ & $\boldsymbol{t}$ & $\boldsymbol{p}$ \\
\hline Self-Esteem & -.03 & -.02 & -.18 & .86 \\
Closeness & .53 & .25 & 2.47 & .02 \\
Self-Esteem $\times$ Closeness & -.65 & -.28 & -2.68 & .009 \\
\hline
\end{tabular}

dramatically lower than the level of threats that have been induced in laboratory studies of dependency regulation (e.g., see Murray et al., 1998). Along these lines, it is worth noting that both people's explicit evaluations of their friends and their reported levels of felt closeness were objectively very high. The mean perceived Rosenberg score participants reported for their best friends was $M=6.32(S D=.64)$, which was slightly higher than participants' own Rosenberg scores. Similarly, the mean closeness score was $M=6.18(S D=.92)$ on a 7-point scale. Apparently, implicit measures such as the name letter measure are highly sensitive even to the kind of small, mundane threats that are a ubiquitous part of almost all relationships.

\section{DISCUSSION}

The results of Study 2 extend our implicit dependency regulation findings to people's relationships with their best friends. That is, people with low explicit self-esteem only evaluated their friends positively when they reported feeling close to their friend. Conversely, people with high explicit self-esteem evaluated their friends positively regardless of how close they felt to their friends. In addition, people's implicit evaluations of their best friend's were independent of their explicit evaluations of them. Moreover, our implicit measure of people's regard for their friends appears to be more sensitive than a comparable explicit measure of people's regard for their friends.

An issue worth considering is whether our results are truly tapping into people's implicit beliefs about others instead of their implicit beliefs about the self. Previous research has shown that people are attracted to and form relationships with other people who share their same name-letters (Pelham, Jones, Mirenberg, \& Carvallo, 2003). Accordingly, if people have friends who share the same first initial as they do, our results may reflect self-regulation in the disguise of dependency regulation. However, when we reran our analyses looking only at people 


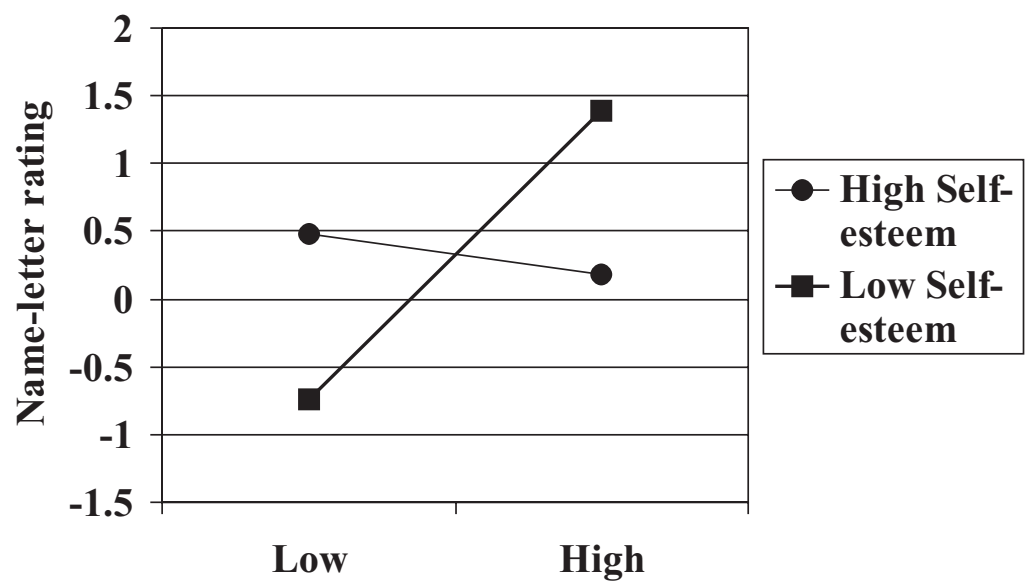

Closeness

FIGURE 2. Predicting best friend's name-letter rating from self-esteem and closeness.

who did not share the same first initials as their friend $(N=78)$, we observed exactly the same pattern of results $(p=.08)$.

On a related note, previous research has found that people who chronically feel less positively regarded by their romantic partners report lower self-esteem on days after they perceive rejection from their partners (Murray et al., 2003a). Consistent with this research, the same Self-esteem $\times$ Closeness interaction was significant when predicting participants liking for their own first name initials, $B=-.51, \beta=-.23, t(95)$ $=-2.30, p=.02$ (see also Jones et al., 2002). Therefore, we wanted to determine whether the findings we observed for people's implicit regard for their friends was independent of their own implicit self-evaluations. We thus repeated the original analysis while controlling for participants' own implicit self-esteem scores. The original Self-esteem $\times$ Closeness interaction was still significant $(p=.03)$. Our results do appear to reflect people's evaluation of their friends rather than their evaluations of themselves. 


\section{GENERAL DISCUSSION}

The present studies extend previous research on the dependency regulation model by suggesting that people's evaluations of their partners become overlearned and are elicited automatically. Specifically, each of our studies showed that people's implicit evaluations of significant others depended on both their level of explicit self-esteem and how close they felt to significant others. Specifically, the implicit evaluation of significant others for people with low explicit self-esteem was contingent on how things were currently going in their relationships. When it came to their implicit evaluations of their partners, people low in self-esteem only seemed to adore their partners when things were going better rather than worse. In contrast, through thick and thin, people high in explicit self-esteem seem to have stuck to their favorable implicit evaluations of significant others.

Although the present findings suggest that dependency regulation processes occur unconsciously, there are at least three further issues to consider. First, restriction of range on the part of our high self-esteem participants in their reports of closeness could account for the lack of an effect of closeness on their implicit evaluations of their significant others. However, self-esteem was not significantly related to how close participants reported feeling toward their romantic partners in Study 1, $r$ $(85)=.15, p=.18$, or toward their friends in Study $2, r(104)=.05, p=.59$. Therefore, restriction of range cannot easily account for our findings.

A second issue to consider is that the causal relations among the variables may be different than the one we have described. We argued that people who are concerned about being rejected by their relationship partners find less to value in their partners as a way to protect the self. On the other hand, it is possible, at least in principle, that people's implicit evaluations of their relationship partners may influence how close they report feeling to their partners. That is, people may report feeling less close to their relationship partners because they have recently devalued them. Although we cannot rule out this possibility on the basis of the present research, prior research has revealed that experimentally-activating concerns about rejection triggers partner devaluation for low, but not high self-esteem people (Murray et al., 2002). Nonetheless, determining the precise causal dynamics of the processes we have documented here will require experimental research.

A third issue worth considering is whether the implicit evaluations we have documented here have any implications for people's behavior. The available evidence suggests that the relation between implicit evaluations of close others and behavior may depend heavily on the social and cognitive context of people's interactions with these close others. For example, people's implicit evaluations are believed to assert their influence under conditions of cognitive load (Koole et al., 2001) and conditions of threat (Bowlby, 1982; Jones et al., 2002; Mikulincer, et al., 
2002; Spalding \& Hardin, 1999). Although we believe that both of these conditions will increase the likelihood that people will rely on their implicit beliefs, we will focus on evidence suggesting the importance of threatening conditions in this process.

First, attachment theory suggests that the attachment system and people's unconscious working models of self and others are activated under threat (Bowlby, 1982; Simpson, Rholes, \& Nelligan, 1992; see also Mikulincer et al., 2002). Second, people's implicit and explicit self-esteem are more highly correlated in response to self-concept threats (Dodgson \& Wood, 1998; Jones et al., 2002). Third, research on implicit self-evaluation suggests that people's implicit self-evaluations may leak into their nonverbal behaviors in response to a self-concept threat (Spalding \& Hardin, 1999). In addition, Gottman and Krokoff (1989) found that the nonverbal behaviors of romantic partners (i.e., facial expressions of emotion and visual gaze patterns) who were discussing problems (a potential threat to the self) in their relationships predicted the likelihood that they would divorce in the future. Therefore, there is some reason to believe that people's implicit evaluations of significant others might be most informative when assessed under threatening conditions.

The current findings are consistent with previous research showing that dependency regulation processes are evident in people's explicit evaluations of their partners (Murray et al., 2002). In fact, we found evidence for dependency regulation processes when people were not focusing on their relationships at all but felt they were merely evaluating the letters of the alphabet. The findings from Study 2 also suggest that dependency regulation processes may occur on an implicit level before they begin to unfold on an explicit level. Presumably, people's implicit beliefs regarding their partners may influence their behavior towards their partners. For example, Murray et al. (2003b) found that married people who felt less positively regarded by their partner reacted to feeling acutely hurt or rejected one day by engaging in negative behaviors toward their partners the next day. Conversely, people who were secure in their partner's acceptance reacted to feeling hurt or rejected one day by drawing closer to their partners on the next day. One unfortunate implication of these findings is that the relationship partners of people who feel less accepted may respond to such negative behavior by actually evaluating their partners more negatively. Ironically, the behavior of people who are insecure about another's acceptance may undermine their partners' ability to sustain positive beliefs about them (Murray, Holmes, \& Griffin, 1996).

The present findings are also consistent with previous research on the relational contingencies of self-esteem (e.g., Crocker \& Wolfe, 2001; Murray et al., 2003a). The need to belong is believed to be a fundamental human motivation (Baumeister \& Leary, 1995). Therefore, it is not all 
that surprising that people's self-esteem is related to how accepted they feel by their close relationship partners (Leary et al., 1995). In the current research we found that people's implicit self-esteem was contingent on their chronic sense of belongingness (i.e., their level of global self-esteem) and how things were currently going in their relationships. This finding is consistent with recent research on explicit self-esteem (Murray et al., 2003a). Our results are also loosely consistent with recent findings that having people focus on extrinsic (i.e., contingent) bases of self-worth is associated with increased defensiveness (see Schimel, Arndt, Banko, \& Cook, current issue).

In addition to supporting and extending the dependency regulation model of close relationships, the current findings also support recent research on the validity and specificity of name letter preferences. First, the dependency regulation findings were stronger for romantic partners' last name initials in Study 1 and for friends' first name initials in Study 2. Because most brides take on their husbands' surnames, it makes a great deal of sense that surnames take on a great deal of psychological significance for married couples. In contrast, first names appear to have more psychological significance among friends. To put these findings in broader terms, they are consistent with past findings that people's first and last names, respectively, serve as separate signs of people's personal and social identities (Hetts \& Pelham, 2003; Kitayama \& Karasawa, 1997; Nuttin, 1985; 1987).

Consistent with this idea, Kitayama and Karasawa (1997) found that unmarried Japanese men liked the letters in their surnames more than did unmarried Japanese women. In contrast, Japanese women liked the letters in their first names more than men did. Kitayama and Karasawa explained this by noting that unmarried Japanese women realize that their surnames are likely to change once they become married (whereas their first names are not; see also Pelham, Mirenberg, \& Jones, 2002). As further evidence that people's first and last names have different psychological meanings, DeHart and Pelham (2003b) found that, relative to children from intact families, children from divorced families disliked their surname initials (and their fathers' first initials) but not their own first name initials. Hetts and Pelham (2003) also showed that, relative to European Americans, members of stigmatized ethnic groups disliked their surname initials (a marker of their social identities) but not their first initials (a marker of their personal identity). Finally, Pelham (2003) found that the degree to which people like their first versus last initials is related to whether they live in a collectivistic versus an individualistic culture (e.g., collectivists show a stronger preference for their surname initials). In short, a great deal of recent evidence suggests that the degree to which people like their first or last initials is strongly linked to the psychological significance of these specific initials. Apparently, the degree 
to which people like the first versus last initials of close others also tells us something about the psychological significance of different names.

Finally, the current results are consistent with previous research demonstrating that people with high self-esteem are good at implicitly regulating their views of themselves (Dodgson \& Wood, 1988; Jones et al., 2002). In addition, this research is also consistent with previous research showing that people with high self-esteem are able to maintain positive beliefs about their romantic partners (Murray et al., 1996; Murray et al., 2002). For people with low self-esteem, of course, the picture is less rosy. The motivation to protect the self against potential hurt and rejection that has been documented on an explicit level seems to be occurring automatically as well. To the degree that this self-protective process occurs automatically, this distressing dynamic may be difficult for people with low self-esteem to change.

\section{REFERENCES}

Aiken L. S., \& West, S. G. (1991). Multiple regression: Testing and interpreting interactions. Newbury Park, CA: Sage.

Andersen, S., \& Chen, S. (2002). The relational self: An interpersonal social-cognitive theory. Psychological Review, 109, 619-645.

Banaji, M. R., \& Hardin, C. D. (1996). Automatic stereotyping. Psychological Science, 7 , 136-141.

Baumeister, R. F., \& Leary, M. R. (1995). The need to belong: Desire for interpersonal attachments as a fundamental human motivation. Psychological Bulletin, 111, 497-529.

Bellavia, G., \& Murray, S. L. (in press). Did I do that? Self-esteem related differences in reactions to a romantic partner's moods. Personal Relationships.

Berscheid, E., \& Fei, J. (1977). Romantic love and sexual jealousy. In G. Clanton \& L. G. Smith (Eds), Jealousy (pp. 101-109). Englewood Cliffs, NJ: Prentice Hall.

Bowlby, J. (1982). Attachment and loss (Volum 1: Attachment). London: Hogarth Press.

Bradbury, T. N., \& Fincham, F. D. (1990). Attributions in marriage: Review and critique. Psychological Bulletin, 107, 3-33.

Crocker, J., \& Wolfe, C. T. (2001). Contingencies of self-worth. Psychological Review, 108, 593-623.

DeHart, T., Murray, S. L., Pelham, B. W., \& Rose, P. (2003). The regulation of dependency in parent-child relationships. Journal of Experimental Social Psychology, 39, 59-67.

DeHart, T., \& Pelham, B. W. (2003a). Self-concept clarity, daily negative events, and the stability of implicit self-esteem. Manuscript in preparation.

DeHart, T., \& Pelham, B. W. (2003b). The hidden effects of early family experiences: The origins of implicit self-esteem. Manuscript in preparation.

Dijksterhuis, A. (in press). I like myself but I don't know why: Enhancing implicit self-esteem by subliminal evaluative conditioning. Journal of Personality and Social Psychology.

Dodgson, P. G., \& Wood, J. V. (1998). Self-esteem and the cognitive accessibility of 
strengths and weaknesses after failure. Journal of Personality and Social Psychology, 75, 178-197.

Gottman, J. M., \& Krokoff, L. J. (1989). Martial interaction and satisfaction: A longitudinal view. Journal of Consulting and Clinical Psychology, 57, 47-52.

Greenwald, A. G., McGhee, D. E., \& Schwartz, J. L. K. (1998). Measuring individual differences in implicit cognition: The implicit association test. Journal of Personality and Social Psychology, 74, 1464-1480.

Hetts, J. J., Sakuma, M., \& Pelham, B.W. (1999). Two roads to positive regard: Implicit and explicit self-evaluation and culture. Journal of Experimental Social Psychology,1-48.

Hetts, J., \& Pelham, B. W. (2003). Stereotypes of the stereotyped: Stigma and implicit self-evaluation. Manuscript in preparation.

Holmes, J. G., \& Rempel, J. K. (1989). Trust in close relationships. In C. Hendrick (Ed), Review of personality and social psychology: Close Relationships, (Vol.10) (pp.187-219). Newbury Park: Sage.

Hoorens, V., \& Nuttin, J. M. (1993). Overvaluation of own attributes: Mere ownership or subjective frequency? Social Cognition, 11, 177-200.

Jones, J. T., Pelham, B. W., Mirenberg, M. C., \& Hetts, J. J. (2002). Name letter preferences are not merely mere exposure: Implicit egotism as self-regulation. Journal of Experimental Social Psychology, 38, 170-177.

Kitayama, S., \& Karasawa, M. (1997). Implicit self-esteem in Japan: Name letters and birthday numbers. Personality and Social Psychology Bulletin, 23, 736-742.

Koole, S. L. (2004). Volitional shielding of the self: Effects of action orientation and external demands on implicit self-evaluation. Social Cognition, 22, 100-125.

Koole, S. L., Dijksterhuis, A., \& van Knippenberg, A. (2001). What's in a name: Implicit self-esteem and the automatic self. Journal of Personality and Social Psychology, 80, 669-685.

Koole, S. L., \& Pelham, B. W. (2002). On the nature of implicit self-esteem: The case of the name letter effect. In S. Spencer, S. Fein, \& M. P. Zanna (2002). Motivated Social Perception: The Ontario Symposium. (Vol. 9, pp. 93-166). Hillsdale, NJ: Lawrence Erlbaum.

Leary, M. R., Tambor, E. S., Terdal, S. K., \& Downs, D. L. (1995). Self-esteem as an interpersonal monitor: The sociometer hypothesis. Journal of Personality and Social Psychology, 68, 518-530.

Mikulincer, M., Gillath, O., \& Shaver, P. R. (2002). Activation of the attachment system in adulthood: Threat-related primes increase the accessibility of mental representations of attachment figures. Journal of Personality and Social Psychology, 83, 881-895.

Murray, S. L., Bellavia, G., Rose, P., \& Griffin, D. (2003b). Once hurt, twice hurtful: How perceived regard regulates daily marital interaction. Journal of Personality and Social Psychology, 84, 126-147.

Murray, S. L., Griffin, D. W., Rose, P., \& Bellavia, G. (2003a). Calibrating the sociometer: The relational contingencies of self-esteem. Journal of Personality and Social Psychology, 85, 63-84.

Murray, S. L., Holmes, J. G., \& Griffin, D. (1996). The benefits of positive illusions: Idealization and the construction of satisfaction in close relationships. Journal of Personality and Social Psychology, 70, 79-98.

Murray, S. L., Holmes, J. G., \& Griffin, D. (2000). Self-esteem and the quest for felt se- 
curity: How perceived regard regulates attachment processes. Journal of Personality and Social Psychology, 78, 478-498.

Murray, S. L., Holmes, J. G., \& Griffin, D., Bellavia, G., \& Rose, P. (2001). The mismeasure of love: How self-doubt contaminates relationship beliefs. Personality and Social Psychology Bulletin, 27, 423-436

Murray, S. L., Holmes, J. G., MacDonald, G., \& Ellsworth, P. (1998). Through the looking glass darkly? When self-doubts turn into relationship insecurities. Journal of Personality and Social Psychology, 75, 1459-1480.

Murray, S. L., Rose, P., Bellavia, G., Holmes, J. G., \& Kusche, A. G. (2002). When rejection stings: How self-esteem constrains relationship-enhancement processes. Journal of Personality and Social Psychology, 83, 556-573.

Nuttin, J. M. (1985). Narcissism beyond Gestalt and awareness: The name letter effect. European Journal of Social Psychology, 15, 353-361.

Nuttin, J. M. (1987). Affective consequences of mere ownership: The name letter effect in twelve European languages. European Journal of Social Psychology, 17, 381-402.

Pelham. B. W. (2003). Implicit egotism and culture. Manuscript in preparation.

Pelham, B. W., Jones, J. T., Mirenberg, M. C., \& Carvallo, M. (2003). The man who took his wife because of an H: Implicit egotism and mate selection. Manuscript in preparation.

Pelham, B. W., Mirenberg, M., \& Jones, J. T. (2002). Why Susie sells seashells by the seashore: Implicit egotism and major life decisions. Journal of Personality and Social Psychology, 82, 469-487.

Robins, R. W., Hendin, H. M., \& Trzesniewski, K. H. (2001). Measuring global self-esteem: Construct validation of a single-item measure and the Rosenberg Self-esteem Scale. Personality and Social Psychology Bulletin, 27, 151-161.

Rosenberg, M. (1965). Society and the adolescent self-image. Princeton, NJ: Princeton University Press.

Schimel, J., Arndt, J., Banko, K. M., \& Cook, A. (in press). Not all self-affirmations were created equal: The cognitive and social benefits of affirming the intrinsic (versus extrinsic) self. Social Cognition, 22, 75-99.

Sedikides, C., \& Green, J. D. (2004). What I don't recall can't hurt me: Information negativity versus information inconsistency as determinants of memorial self-defense. Social Cognition, 22, 4-29.

Simpson, J., Ickes, W., \& Blackstone, T. (1995). When the head protects the heart: Empathic accuracy in dating relationships. Journal of Personality and Social Psychology, 69, 629-641.

Simpson, J., Rholes, W., \& Nelligan, J. (1992). Support seeking and support giving within couples in an anxiety provoking situation: The role of attachment styles. Journal of Personality and Social Psychology, 62, 434-446.

Spalding, L. R., \& Hardin, C. D. (1999). Unconscious unease and self-handicapping: Behavioral consequences of individual differences in implicit and explicit self-esteem. Psychological Science, 10, 535-539.

Stapel, D. A., \& Schwinghammer, S. A. (2004). Defensive social comparisons and the constraints of reality. Social Cognition, 22, 147-167.

Wentura, D., \& Greve, W. (2004). Who wants to be...well-educated? Everyone! Evidence for automatic adaptation of trait definitions. Social Cognition, 22, 30-53. 